deafness, then the paraphasia, then the bad grammar, lastly, the difficulty of finding the proper words. A second attack, with symptoms of leftsided hemiplegia, again brought back these speech disorders, which again subsided, leaving behind a persistent word-deafness. The description of this case occupies thirty-five pages, in which the whole power of language and appreciation of tone are most carefully analysed.

Bonvicini presents the following conclusions: Word-deafness may be caused both by peripheral and central lesions affecting the middle ear, the labyrinth, both acoustic nerves, and the nerve-tracts leading to the cortex, as well as of the auditory zones at both sides of the brain. In all these cases we have to do with a false, sensory, acoustic word-deafness which is different from the pure speech-deafness described by Wernicke and Lichtheim. If, on examining the power of hearing, one finds a sufficient perception of tones, he may conclude that the worddeafness is independent of a general impairment of hearing, and if the power of repeating words and of writing to dictation be lost, while the spontaneous use of the voice, reading, and writing remains intact, we have the clinical form of subcortical sensory aphasia.

The cause of this pure word-deafness lies either in a one-sided affection, when a lesion in the white matter of the left temporal lobe occasions a sub-cortical interruption of the auditory projection path and of the connection of the auditories' spheres through the corpus callosum, or it consists in an affection of the temporal lobe on two sides of the brain, which disturbs the paths without injuring the cortex. We can only cite two instances of sub-cortical sensory aphasia from a unilateral lesion-Liepmann's case, of which we have the anatomical investigation, and the case described by van Gehuchten and Goris, which went no further than clinical observation. We cannot produce from the literature of the subject a single unimpeachable instance of word-deafness of bilateral origin, for the cases hitherto presented as such either fail in the symptoms of pure word-deafness or are attended by difficulties of speech which seem capable of hindering the apprehension of speech. Bonvicini considers the case described by him, although the anatomical confirmation is wanting, to be the only one where the symptoms of sub-cortical sensory aphasia are decided and uncomplicated. They have persisted unaltered for years, and the tests show a scarcely appreciable diminution of hearing. Heretofore the cases of word-deafness examined by Bezold's method have all shown an equal though slight impairment of the perception of tone in all the octaves of the scale.

William W. IRELAND.

\title{
Upon the Influence of Mental Processes upon Metabolism [Ueber den Einfluss psychischer Vorgänge auf den Stoffwechsel]. (Allgem. Zeits. f. Psychiat., Bd. lxiii, H. 3. Rosenfeld.
}

In a paper of above thirty pages Dr. Rosenfeld considers this subject both in its physiological and pathological aspects. He cites the labours of many investigators, from which it appears that it is difficult to prove that the quantity of blood in the brain is increased in mental activity. In nerve-tissue the changes are small and the restitution is speedy. 
The difficulty of separating the share of the excretions from the total furnished by the muscular and nutritive activities is too great to allow of a definite conclusion. Rosenfeld observes: "It has not been shown that the chemical changes in the brain, which are not necessarily processes of oxidation, have a recognisable influence upon common metabolism, nor can it be proved that the changes in the composition of the urine noted by some inquirers are the direct result of these chemical changes."

Rosenfeld then goes on to inquire whether alterations in the composition of the urine have been found to follow pathological conditions of the brain.

He cites many investigations by various authors; amongst others Koppen has constantly found albuminuria in acute deliria and sometimes propepton. The specific gravity was about 1030, but there was no constant relation between it and the quantity of albumen. Albuminuria was in delirium tremens and other cerebral disorders. Peptonuria has been frequently observed in general paralysis, but in this disease Rosenfeld has neither found this nor albuminuria constant. Tuzek could find no albuminuria in insane patients during periods of abstinence, and Schäfer failed to find it in circular insanity. Acetonuria has been observed in some cases of paralysis and other mental derangements, probably the result of low nutrition. Glycosuria has been frequently observed in insane patients, but not in any special form of insanity. Raimann has made inquiries into the assimilation of sugar in different forms; he has experimented on the assimilating power shown by the appearance of glycosuria after the administration of so much grape sugar calculated upon each kilo of the body weight. In idiocy this assimilative power was calculated at 4.7 ; in maniacal patients it was from $3 \cdot 9$ to 6.6 . In acute confusional insanity from $2 \cdot 7$ to $I^{\circ} 4$, and in melancholia from $I^{\cdot} 2$ to $I^{\circ} 9$. This low grade in melancholiacs he regards as owing to the slowness of the vital processes.

WILliam W. IRELAND.

\section{Mental Degeneracy [De la Dégénérescence Mentale]. (Rev. de Psychiat., October, 1905.) Marchand.}

Morel employed the term "degeneracy" to indicate any departure from the primitive human type, apart from such as resulted in a better adaptation to the environment. He considered its principal character to be hereditary transmission, and that it became progressively more accentuated in the descendants, ultimately leading to sterility. The cause was to be found in various ancestral diseases and intoxications. He classified the cases into two groups : those with physical malformations and intellectual enfeeblement (idiots, imbeciles, cretins); and those with various psychical affections (obsessions, eccentricities, distortion of moral sense, etc.), but without intellectual enfeeblement.

Magnan attaches less importance to heredity. He thinks that all the manifold varieties are reducible at bottom to one psychopathic modea failure of psychical equilibrium.

The term "mental degeneracy" is accepted by modern psychiatry, nevertheless it is difficult to apply in practice. One must recognise 